\title{
An estimate of the effect of acute exsanguination on catecholamine and glucoregulatory hormone concentrations in the newborn rat
}

\author{
R. D. Jansen and H.C. Moorehead \\ Department of Pediatrics, Indiana University School of Medicine, Indianapolis, Indiana, USA
}

\begin{abstract}
Summary. We have determined the effect of acute exsanguination on plasma concentrations of glucose, insulin, glucagon, dopamine, epinephrine and norepinephrine in neonatal Sprague-Dawley rats. This was done by comparing concentrations of these substances in aliquots of blood obtained within $10 \mathrm{~s}$ of the initial bleeding to those in blood obtained over the next $50 \mathrm{~s}$ of the blood drawing process. Concentrations of glucose and insulin showed no change between early and late samples. Glucagon concentrations showed variable responses dependent upon the age of the animal. Concentrations were unchanged at birth, but increased $22 \%$ and $58 \%$ at 1 and $6 \mathrm{~h}$ of
\end{abstract}

age respectively. Catecholamine concentrations increased greatly ( 57 to $215 \%$ ) between blood aliquots regardless of age at the time of sampling. These findings indicate that hormonal responses occur during the relatively brief period of blood drawing in Sprague-Dawley rats, pointing out further limitations inherent in the use of small animals for acute metabolic and hormonal studies.

Key words: Glucoregulatory hormones, newborns, haemorrhage.
Fetal and neonatal rat pups have been subjects of numerous studies characterizing glucoregulatory adaptions in the perinatal period. Girard et al. [1] and Girard and Sperling [2] have reviewed the results of many such studies. Due to the small size of rats at this stage of development, such studies uniformly involve the collection of only one sample of blood from individual animals at a single point in time. This is due to the fact that the measurement of circulating metabolic fuels or hormones in this animal requires the collection of a substantial quantity of blood relative to the pup's size. Often essentially complete exsanguination is necessary if concentrations of hormones or of multiple substrates are to be assayed. However, the effects of the blood drawing process itself on circulating concentrations of these substances has not been evaluated. In larger animals haemorrhage is recognized to acutely affect concentrations of some of metabolites and hormones [3, 4]. Such metabolites and hormones often have been of interest to those using newborn rats as subjects. This report provides an estimate of the effect of the blood drawing process on plasma concentrations of glucose, insulin, glucagon, dopamine, epinephrine and norepinephrine in neonatal rats.

\section{Materials and methods}

Primiparous timed-pregnant Sprague-Dawley rats (Harlan Industries, Indianapolis, IN, USA) were allowed unrestricted access to water and a standard rat chow (Purina, St. Louis, MO, USA). The duration of pregnancy was estimated from the assumed time of ovulation, which usually occurred between midnight and $03.00 \mathrm{~h}$ the night of cohabitation with a male. At approximately 21.5 days gestation (term $=22$ ), maternal rats were delivered by hysterotomy after they were killed by cervical dislocation. Pups were carefully dried and their placentas removed. A heating blanket and a heat lamp were used at delivery and at the subsequent times of blood drawing to avoid cold stress. Following delivery, the pups were transferred to a humidicrib maintained at $36{ }^{\circ} \mathrm{C}, 70 \%$ relative humidity. The pups had carcass weights between 5.2 and $6.0 \mathrm{~g}$ (mean \pm standard deviation, $5.53 \pm 35 \mathrm{~g}$ ). These weights were in close agreement with those of pups born spontaneously at term in our laboratory. Litters were randomly utilized for insulin, glucagon or catecholamine determinations. Within each litter, littermates were selected so as to have roughly equivalent numbers of pups [3-4] at each sampling time.

Blood was collected from individual pups within 2 min of birth, at $1 \mathrm{~h}$, or a $6 \mathrm{~h}$ age. Pups were gently removed from the humidicrib and an axillary incision was made to transect the axillary vessels. Freeflowing blood was collected in two parts: (A), blood collected in the first 10 s after incision (early collection); and (B), blood collected over the subsequent $50 \mathrm{~s}$ (late collection). This division provided essentially equal aliquots of blood. There was no difference in bleeding rates among the three times of sampling. Following the blood drawing the pups were killed by decapitation.

All blood samples were collected in chilled heparinized capillary tubes. Blood for insulin and glucagon assays was collected with Trasy$101,25: 1 \mathrm{v} / \mathrm{v}$, and immediately centrifuged. Plasma was rapidly frozen and stored at $-70^{\circ} \mathrm{C}$ until the time of assay. Blood for plasma catecholamine determinations was collected with EGTA [ethylene glycolbis ( $\beta$-amino-etheyl ether) $\mathrm{N}, \mathrm{N}, \mathrm{N}^{\prime}, \mathrm{N}^{\prime}$ tetra-acetic acid], centrifuged immediately, and the plasma frozen and stored at $-70^{\circ} \mathrm{C}$.

Plasma glucose concentrations were determined by a glucose oxidase technique (Beckman Glucose Analyzer, Beckman Instruments, Fullerton, CA, USA). Plasma catecholamine concentrations were determined using a radioenzymatic technique (Cat-a-Kit, Upjohn Diag- 
nostics, Kalamazoo, MI, USA) [5]. Plasma insulin was measured using a double antibody radioimmunoassay system employing rat insulin standards (Novo Laboratories, Inc., Copenhagen, Denmark) [6]. Plasma glucagon concentrations were determined with a double antibody radioimmunoassay using porcine glucagon as standard (Eli Lilly Company, Indianapolis, IN, USA) and employing $30 \mathrm{~K}$ antibody (obtained from Dr. R. Unger) [7]. The assay system was modified for small sample volumes as by Bussey et al. [8].

Paired A and B samples (early and late collections respectively) were assayed together for each measured substance. All insulin concentrations were determined in a single assay, as were glucagon concentrations.

Because the plasma volumes obtained were small, only one hormonal assay (insulin, glucagon, or catecholamines) was performed on each sample. Where volumes allowed, plasma glucose was determined in each specimen. Also because of sample volume limitations, glucagon determinations were done using plasma samples from paired littermates. That is, equal aliquots of early- and late-drawn plasma were paired with those of a littermate and the plasma specimens thawed, combined, mixed well, and then assayed.

Coefficients of intra- and inter-assay variation in our laboratory are $3 \%$ and $11 \%$ for glucose and catecholamines respectively. Intra-assay coefficients of variation are $10 \%$ and $13 \%$ for insulin and glucagon respectively.

\section{Statistical analysis}

Paired data were analyzed by two-tailed paired Student's t-tests, and compared early collection blood (A) with late collection blood (B) at each time of drawing. Data are presented as means \pm one standard deviation of the mean (mean $\pm S D$ ). P values of greater than 0.05 were considered as insignificant (NS).

\section{Results}

A summary of the results is given in Table 1. Plasma glucose concentrations did not show statistically significant differences between the early (A) and late (B) paired collection samples at any of the three sampling times. Early and late collection plasma insulin concentrations similarly were not different at any of the sampling times.

However, statistically significant increases in concentrations of glucagon and catecholamines were noted when early and late samples were compared. Plasma glucagon showed mean increases of $22 \%$ and $58 \%$ between early and late specimen pairs at $1 \mathrm{~h}$ and $6 \mathrm{~h}$ respectively $(p<0.05)$, although at birth glucagon concentrations in A and B samples were not different. Plasma epinephrine concentrations were greatly increased in B samples, with increases of $122 \%, 215 \%$, and $165 \%$ above the corresponding A samples at birth $(p<0.05), 1 \mathrm{~h}$ $(p<0.05)$ and $6 \mathrm{~h}(p<0.01)$ respectively. Norepinephrine concentrations also increased between sample pairs, although to a lesser extent than epinephrine. Mean increases in norepinephrine were $69 \%$ at birth $(p<0.05), 58 \%$ at $1 \mathrm{~h}(p<0.01)$, and $106 \%$ at $6 \mathrm{~h}(p<$ $0.01)$. Plasma dopamine concentrations similarly increased between sample pairs. Mean increases were $57 \%$ at birth $(p<0.05), 132 \%$ at $1 \mathrm{~h}(p<0.01)$, and $96 \%$ at $6 \mathrm{~h}(p<0.01)$.
Table 1. Plasma glucose, hormone and catecholamine concentrations in early (A) and late (B) blood collection samples

\begin{tabular}{|c|c|c|c|c|c|c|c|c|}
\hline \multirow[b]{3}{*}{ Glucose $(\mathrm{mol} / \mathrm{l})$} & \multicolumn{8}{|c|}{ Time of blood drawing } \\
\hline & \multicolumn{3}{|l|}{ Birth } & \multicolumn{2}{|l|}{$1 \mathrm{~h}$} & \multicolumn{3}{|l|}{$6 \mathrm{~h}$} \\
\hline & & & \multirow[b]{2}{*}{0.73} & \multirow[b]{2}{*}{1.01} & \multirow[b]{2}{*}{$\pm \quad 0.41$} & \multirow{2}{*}{\multicolumn{2}{|c|}{$4.21 \pm$}} & \multirow[b]{2}{*}{0.75} \\
\hline $\mathrm{A}($ mean $\pm \mathrm{SD})$ & \multicolumn{2}{|c|}{$3.36 \pm$} & & & & & & \\
\hline $\mathrm{B}($ mean $\pm \mathrm{SD})$ & & $41 \pm$ & 0.73 & & $99 \pm 0.37$ & 4.29 & & 0.74 \\
\hline $\begin{array}{l}{ }^{a} \text { Mean difference } \\
(\% \pm \% \text { SD })\end{array}$ & & $5 \pm$ & 5.0 & -2.0 & $0 \pm 24.1$ & 2.1 & & 4.3 \\
\hline$n=$ & \multicolumn{3}{|c|}{23} & \multicolumn{2}{|r|}{22} & \multicolumn{3}{|c|}{20} \\
\hline$p$ & \multicolumn{3}{|c|}{ NS } & \multicolumn{2}{|r|}{ NS } & \multicolumn{3}{|c|}{ NS } \\
\hline \multicolumn{9}{|l|}{ Insulin $(\mu \mathrm{U} / \mathrm{ml})$} \\
\hline $\mathrm{A}($ mean $\pm \mathrm{SD})$ & 85.6 & $6 \pm$ & 22.6 & 19.6 & $6 \pm 8.3$ & 8.9 & & 4.6 \\
\hline $\mathrm{B}($ mean $\pm \mathrm{SD})$ & 83.6 & $6 \pm$ & 22.0 & 20.3 & $3 \pm 9.5$ & 8.7 & \pm & 2.1 \\
\hline $\begin{array}{l}\text { Mean difference } \\
(\% \pm \% \text { SD })\end{array}$ & -0.6 & $6 \pm$ & 19.0 & & $25 \pm 1.1$ & 18.5 & \pm & 52.5 \\
\hline$n=$ & & 12 & & & 13 & & 14 & \\
\hline$p$ & & NS & & & NS & & NS & \\
\hline \multicolumn{9}{|l|}{ Glucagon $(\mathrm{pg} / \mathrm{ml})$} \\
\hline $\mathrm{A}($ mean $\pm \mathrm{SD})$ & 190.4 & $4 \pm$ & 55.6 & 182.0 & $0 \pm 49.2$ & 139.4 & & 72.3 \\
\hline $\mathrm{B}($ mean $\pm \mathrm{SD})$ & 185.7 & $7 \pm$ & 50.3 & 217.8 & $8 \pm 58.6$ & 183.7 & \pm & 27.6 \\
\hline $\begin{array}{l}\text { Mean difference } \\
(\% \pm \% \mathrm{SD})\end{array}$ & -0.7 & $7 \pm$ & 14 & 22 & \pm 27 & 58 & \pm & 64 \\
\hline$n=$ & \multicolumn{3}{|c|}{12} & \multicolumn{2}{|c|}{11} & \multicolumn{3}{|c|}{11} \\
\hline$p$ & \multicolumn{3}{|c|}{ NS } & \multicolumn{2}{|c|}{$<.05$} & \multicolumn{3}{|c|}{$<.05$} \\
\hline \multicolumn{9}{|l|}{ Dopamine (pg/ml) } \\
\hline $\mathrm{A}($ mean $\pm \mathrm{SD})$ & 753 & \pm 1 & 135 & 312 & \pm 64 & 391 & \pm & 52 \\
\hline $\mathrm{B}($ mean $\pm \mathrm{SD})$ & 1185 & \pm 1 & 136 & 725 & \pm 82 & 770 & \pm & 175 \\
\hline $\begin{array}{l}\text { Mean difference } \\
(\% \pm \text { SD })\end{array}$ & 57 & \pm & 20 & 132 & \pm 24 & 96 & \pm & 47 \\
\hline$n=$ & & 10 & & & 9 & & 10 & \\
\hline$p$ & & .01 & & & .001 & $<.0$ & 01 & \\
\hline Epinephrine $(\mathrm{pg} / \mathrm{ml})$ & & & & & & & & \\
\hline $\mathrm{A}($ mean $\pm \mathrm{SD})$ & 5575 & \pm 4 & 1416 & 801 & \pm 291 & 1489 & \pm 8 & 800 \\
\hline $\mathrm{B}($ mean $\pm \mathrm{SD})$ & 8466 & \pm 38 & 3842 & 2251 & \pm 897 & 3545 & & 1654 \\
\hline $\begin{array}{l}\text { Mean difference } \\
(\% \pm \% \text { SD })\end{array}$ & 122 & \pm 1 & 151 & 215 & \pm 164 & 164 & \pm & 90 \\
\hline$n=$ & & 10 & & & 9 & & 10 & \\
\hline$p$ & & .05 & & & .05 & $<.0$ & 001 & \\
\hline $\begin{array}{l}\text { Norepinephrine } \\
(\mathrm{pg} / \mathrm{ml})\end{array}$ & & & & & & & & \\
\hline $\mathrm{A}($ mean $\pm \mathrm{SD})$ & 2876 & \pm 13 & 1331 & 901 & \pm 340 & 801 & \pm & 473 \\
\hline $\mathrm{B}($ mean $\pm \mathrm{SD})$ & 4489 & \pm 15 & 1553 & 1294 & \pm 248 & 1402 & \pm & 527 \\
\hline $\begin{array}{l}\text { Mean difference } \\
(\% \pm \% \text { SD })\end{array}$ & 69 & \pm & 46 & 58 & \pm 53 & 107 & \pm & 96 \\
\hline$n=$ & & 10 & & & 9 & & 10 & \\
\hline$p$ & & .05 & & & .01 & $<0$ & 0.1 & \\
\hline
\end{tabular}
a Mean difference $(\%)$ calculated as $\frac{\mathrm{B}-\mathrm{A}}{\mathrm{A}} \times 100 ;{ }^{\mathrm{b}} n=$ number of sample pairs
assayed

\section{Discussion}

The newborn rat has been the subject of extensive study with regard to glucoregulatory events occurring in the immediate neonatal period. Key to the achievement of glucose homeostasis is a fall in insulin from high fetal levels to low basal concentrations, as well as a surge in glucagon secretion $[1,9,10]$. These hormonal events occur within the first hour of life, and the surge in glucagon has been related to the increase in catecholamines occurring at delivery $[2,11,12]$. The above studies have used non-anaesthetized animals whose blood was collected either after incision of axillary vessels or from the neck at decapitation. Several investigations have documented that the interpretation of data obtained from such "acute preparations" used for physiologic or meta- 
bolic studies potentially may be fraught with error [13-15].

The study reported here was designed to determine whether glucose, insulin, glucagon or catecholamine concentrations are affected by the blood drawing process. This was done by comparing concentrations of these substances in blood obtained in the first $10 \mathrm{~s}$ of the blood drawing process with those in blood obtained over a subsequent 50 -s period. This division of the collection time was selected because it resulted in approximately equal quantities of blood being obtained in each portion of the paired samples. Also, the free flow of blood is essentially complete by the end of $1 \mathrm{~min}$. A technique using axillary incision was used, since the blood obtained would be relatively free from contamination. Blood collected from the neck after decapitation is necessarily admixed with cerebrospinal fluid and pharyngeal secretions. Finally, three sampling times were evaluated in order to determine whether any observable effects of the blood drawing might be influenced by the stage of adjustment to extrauterine life. At birth, insulin $[9,10]$ and catecholamines [11] are high, subsequently falling rapidly. At $1 \mathrm{~h}$ of age, hypoglycaemia is evident, glucagon has surged and insulin is at basal levels $[1,9,10]$. At $6 \mathrm{~h}$, glucose concentrations have stabilized, as have concentrations of insulin, glucagon and catecholamines [1, 9-12].

The data presented indicate that plasma glucose concentrations are equivalent in early and late samples regardless of the timing of the blood draw. Similarly, no detectable change in insulin concentration occurred during the blood sampling, regardless of whether concentrations were high as at birth or low as in the later times of sampling. Although "stress" situations are well known to lead to increased glucose and decreased release of insulin [16, 17], the duration of the total sampling time in this study was relatively brief and apparently insufficient for such variations to be detected.

Increases in glucagon and catecholamines were detected. Glucagon concentrations have been recognized to increase in response to exsanguinating haemorrhage accomplished over 40-70 min [3, 4]. Adrenergic stimulation of glucagon secretion has been considered to be the mechanism responsible for the increase in glucagon concentration [4]. Our data indicate that glucagon concentrations increase within the relatively brief period of the blood collection technique used here, during which time exsanguination rapidly occurs. Since catecholamine concentrations also increased greatly during the blood drawing process, it is likely that adrenergic effects were responsible for the increase in glucagon observed at the 1- and 6-h sampling times. The apparent failure of glucagon to increase with exsanguination at birth may relate to the finding that catecholamine concentrations were already extremely high. Thus, the further increase in catecholamines with haemorrhage may not have provided an additional adrenergic stimulation for glucagon secretion.
Glucagon concentrations at $1 \mathrm{~h}$ did not reflect the postnatal surge of this hormone as has been well described [1,9-12]. In an earlier study in our laboratory [19], glucagon concentrations in non-asphyxiated rats did surge during the first hour of life, being substantially elevated at 20 and $40 \mathrm{~min}$, but returned by $60 \mathrm{~min}$ to a level similar to that at birth. In the present study, if values from early and late specimens are averaged, the mean glucagon concentration at $1 \mathrm{~h}$ of $206 \pm 41 \mathrm{pg} / \mathrm{ml}$ is not statistically different from the mean concentration at birth of $190 \pm 50 \mathrm{pg} / \mathrm{ml}$ ( $p=40$ by 2-tailed non-paired Student's t-test). These values are in close agreement with our earlier results [19].

Catecholamine concentrations also increased in response to blood drawing. Epinephrine and norepinephrine concentrations were consistently higher in blood obtained in the later portion of each sampling. The fetus and neonate of various species are capable of responding to stress with rapid increases in catecholamines [11, 18-21]. Our findings indicate that the neonatal rat responds to the stress of blood drawing with a very large increase in circulating catecholamines. The increase in epinephrine was proportionately greater than the increase in norepinephriene.

Our findings indicate further limitations inherent in the use of small animals for acute metabolic or hormonal studies. Although it is reassuring that glucose and insulin concentrations apparently did not change over the course of the blood drawing process, the glucagon and catecholamine data indicate that concentrations of these latter substances do undergo change during exsanguination. Also, as suggested by the variable effects on glucagon, the extent to which these changes occur may vary with the time at which samples are obtained in relation to birth. Finally, it should be recognized that the early-collected portion of the specimen pairs cannot be taken to be an absolute basal value, as even the brief handling necessary to obtain blood may potentially produce alterations in the concentrations of substances to be assayed.

Acknowledgement. Supported in part by 2P60AM20542 from the National Institute of Health and the Riley Memorial Association.

\section{References}

1. Girard JR, Ferre P, Kervran A, Pegorier JP, Assay R (1977) Role of the insulin/glucagon ratio in the changes of hepatic metabolism during development of the rat. In: Foa PP, Bajaj JS, Foa NL (eds) Glucagon: its role in physiology and clinical medicine. Springer, New York, pp 563-581

2. Girard J, Sperling M (1983) Glucagon in the fetus and the newborn. In: Lefebvre PJ (ed) Handbook of experimental pharmacology. Glucagon II. Springer, New York, pp 251-274

3. Halmagyi DFJ, Neering IR, Lazarus L, Young JD, Pullin J (1969) Plasma glucagon in experimental posthemorrhagic shock. J Trauma 9: $320-326$

4. Lindsey CA, Faloona GR, Unger RH (1975) Plasma glucagon levels during rapid exsanguination with and without adrenergic blockade. Diabetes 24: 313-316 
5. Peuler JC, Johnson GA (1977) Simultaneous single isotope radioenzymatic assay of plasma norepinephrine, epinephrine and dopamine. Life Sci 21: 313-316

6. Soeldner JS, Slone D (1968) Critical variables in the radioimmunoassays of serum insulin using the double antibody technic. Diabetes 14: 771-779

7. Unger RH, Aguilar-Parada E, Muller WA, Eisentraut AM (1970) Studies of pancreatic alpha cell function in normal and diabetic subjects. J Clin Invest 49:837-848

8. Bussey ME, Finley S, LaBarbera A, Ogata ES (1985) Hypoglycemia in the newborn growth-retarded rat: delayed phosphoenolpyruvate carboxykinase induction despite increased glucagon availability. Pediatr Res 19:363-367

9. Girard JR, Guendet GS, Marliss EB, Kervran A, Rieutort M, Assan R (1973) Fuels, hormones and liver metabolism at term and during the early postnatal period in the rat. J Clin Invest 52: $3190-3200$

10. Snall K, Walker DG (1978) Glucose metabolism in the newborn rat: the role of insulin. Diabetolgogia 14: 59-64

11. Cuezva JM, Burkett ES, Kerr DS, Rodman HN, Patel MS (1982) The newborn of diabetic rat. I. Hormonal and metabolic changes in the postnatal period. Pediatr Res 16:632-637

12. Girard JR, Kervran A, Soufflet E, Assan R (1974) Factors affecting the secretion of insulin and glucagon by the rat fetus. Diabetes 23: 310-317

13. Clapp JF III, Abrams RM (1978) Energy metabolism in the exteriorized fetus. Gynecol Obstet Invest 9: 32-39

14. Lemons JA, Perez R, Schreiner RL, Gresham EL (1980) Acute small animal preparation-suitable for fetal metabolic studies? J Appl Physiol: Respir Environ Exercise Physiol 49: 42-44

15. Rudolph AM, Heymann MA (1967) The circulation of the fetus in utero. Methods for studying distribution of blood flow, cardiac output and organ blood flow. Circ Res 21: 163-184
16. Felig P, Sherwin RS, Soman V, Wahren J, Hendler R, Sacca L, Eigler N, Goldberg E, Walesky M (1979) Hormonal in teractions in the regulation of blood glucose. Recent Prog Horm Res 35: 501-532

17. Halter JB, Beard JC, Porte D Jr (1984) Islet function and stress hyperglycemia: plasma glucose and epinephrine interaction. Am J Physiol 247: E47-52

18. Cohen WR, Piasecki GJ, Cohn HE, Young JB, Jackson BT (1984) Adrenal secretion of catecholamines during hypoexemia in fetal lambs. Endocrinology 114: 383-390

19. Jansen RD, Hayden MK, Ogata ES (1984) Effects of asphyxia at birth on postnatal glucose regulation in the rat. J Dev Physiol 6: 473-483

20. Lagercrantz H (1984) Catecholamine surge at birth in the human infant. In: Catecholamines: basic and peripheral mechanisms, Alan R Liss, New York, pp.113-120

21. Lewis AB, Wolf WJ, Sischow W (1984) Cardiovascular and catecholamine responses to successive episodes of hypoxemia in the fetus. Biol Neonate 45: 105-111

Received: 16 November 1985

and in revised form: 2 April 1986

Dr. Robert D. Jansen

Department of Pediatrics

Prentice Women's Hospital

Room 464

333 East Superior Street

Chicago IL 60611

USA 